\title{
Infectious Pathology of the Scrotum in Abidjan: Ultrasound Features of 80 Cases
}

\author{
N'goran Kouame, Fotso Sorel Manewa, Amlan Marie-France Kouame, \\ Anne-Marie N'goan-Domoua, Roger-Daniel N'gbesso \\ Department of Radiology, Yopougon University Hospital, Abidjan, Cote d'Ivoire \\ Email:kngoran@yahoo.fr
}

How to cite this paper: Kouame, N., Manewa, F.S., Kouame, A.M.-F., N'goanDomoua, A.-M. and N'gbesso, R.-D. (2017) Infectious Pathology of the Scrotum in Abidjan: Ultrasound Features of 80 Cases. Open Journal of Radiology, 7, 103-111. https://doi.org/10.4236/ojrad.2017.72012

Received: March 28, 2017

Accepted: June 12, 2017

Published: June 15, 2017

Copyright $\odot 2017$ by authors and Scientific Research Publishing Inc. This work is licensed under the Creative Commons Attribution International License (CC BY 4.0).

http://creativecommons.org/licenses/by/4.0/

\begin{abstract}
Objectives: The aim of this study was to determine the epidemiological-clinical profile of patients with scrotal infectious pathology in Abidjan and describe the ultrasound features of this scrotal infectious pathology. Methods: This was a prospective study of 80 cases of scrotal infectious pathology objectified by ultrasound at Yopougon University Hospital from 1 January 2015 to 31 December 2015. Ultrasounds were performed using a high-frequency linear probe in B and Color Doppler modes by senior radiologists. The epidemiological-clinical data were recorded from the ultrasound request form and the interrogation of the patient. Results: The average age was 23 years with extreme ranging from 16 to 40 years. Soldiers were the most concerned (40\%) followed by students (30\%). The painful large bursa was the quasi constant presenting feature (95\% of cases) and fever was associated in less than half of the cases ( $45 \%$ of cases). The scrotal involvement was most often unilateral ( $85 \%$ of cases) and the left side was involved in $70 \%$ of the cases. Epididymitis was the most frequent pathology (60\%) followed by orchiepididymitis (30\%) and orchitis (10\%). The most commonly encountered accompanying ultrasound findings were envelope thickening (100\%), intravaginal fluid effusion (60\%), and Doppler Hypervascularization (30\%). Conclusion: In Abidjan Scrotal infectious pathology is most often encountered among young soldiers or students most often with a \pm febrile large bursa. The most common pathology is left unilateral epididymitis.
\end{abstract}

\section{Keywords}

Orchitis, Epididymitis, Large Bursa, Male Genital Infection

\section{Introduction}

Scrotal pathology is common in both children and adults. It concerns nearly 200 reasons for consultation in Switzerland [1]. In Mali, it constitutes 5.5\% of uro- 
logical consultations [2]. Its etiologies are numerous [3]. The spectrum of pathologies involving the scrotum and its contents extends from benign lesionswhere you just need to reassure the patient- to severe lesions (tumor, torsion), whose management must be carried out for some in extreme urgency [1]. Infections are part of this varied range of scrotal pathology in which they are predominant in sub-Saharan Africa [2]. Scrotal infections are defined as the involvement of scrotal content in relation to banal or specific organisms such as tuberculosis [4]. Their management must be carried out urgently and in a multidisciplinary facility because of their unpredictable evolution, which can be lifethreatening (by septicemia) or lead to sterility.

The diagnosis of scrotal infectious pathology requires in an unavoidable way medical imaging represented by Doppler ultrasound and magnetic resonance imaging [1] [3]. Indeed, more requested than MRI, Doppler ultrasound helps with positive diagnosis, lesion assessment, search for complications and differential diagnosis with the other non-infectious diseases [1]. A good knowledge of ultrasound scanning of scrotal infections is necessary to reduce the proportion of unnecessary surgical exploration (1.5), given the unavailability of MRI in our countries and the black African specificities marked by late consultations.

It is in this context that our study proposes to determine the epidemiological and clinical profile of patients with scrotal infectious pathology and to describe the ultrasound features of the scrotal infectious pathology in Abidjan.

\section{Patients and Methods}

This is a prospective study that was carried out over a twelve-month period from 1 January 2015 to 31 December 2015 at Yopougon University Hospital. It involved all patients in whom a scrotal infectious pathology was discovered on the ultrasound scan. Ultrasounds were performed using a high frequency linear probe in B and color Doppler modes by senior radiologists. The epidemiological data were recorded from the ultrasound request form and the interrogation of the patient. The variables sought were age, occupation, previous history of sexually transmitted infections (STI) or urinary tract infection, notion of fever, direct and indirect ultrasound findings. The interpretation of the ultrasound findings was based on measuring the size of testes, epididymises and envelopes. It is also necessary to assess the echostructure of the different intra-scrotal structures, to seek intravaginal fluid effusion. We also assessed the vascularization of the different intra scrotal components without performing a thorough spectral analysis. Eight patients underwent urinary sampling, 5 sperm culture and 1 cytobacteriological examination of the urine. Data were processed by Statistical Package for the Social Sciences (SPSS) software version 16.0.

\section{Results}

All of our results are summarized in Tables 1-6.

A total of 80 patients were involved in our study. The average age of patients was 23 years with extremes of 16 to 40 years. Soldiers were the most concerned 
Table 1. Distribution according to age groups.

\begin{tabular}{ccc}
\hline AGE (year) & EFFECTIVE & PERCENTAGE \% \\
\hline $16-20$ & 18 & 22.5 \\
$21-25$ & 41 & 51.3 \\
$26-30$ & 6 & 7.5 \\
$31-35$ & 8 & 10 \\
$36-40$ & 7 & 8.7 \\
TOTAL & $\mathbf{8 0}$ & 100
\end{tabular}

The mean age was 23 years with a predominance of the age group between 21 and 25 years. No case was found before 15 years.

Table 2. Overall Distribution according to the occupation.

\begin{tabular}{ccc}
\hline OCCUPATION & EFFECTIVE & PERCENTAGE \% \\
\hline Soldiers & 32 & 40 \\
Students & 24 & 30 \\
Mechanics & 5 & 6.3 \\
Tradespeople & 7 & 8.7 \\
Drivers & 8 & 10 \\
Other & 4 & 5 \\
TOTAL & $\mathbf{8 0}$ & 100 \\
\hline
\end{tabular}

Soldiers were the most concerned (40\%) followed by students (30\%).

Table 3. Distribution according to the indication.

\begin{tabular}{ccc}
\hline INDICATION & EFFECTIVE & PERCENTAGE \% \\
\hline Painful swelling & 76 & 95 \\
Isolated scrotal pain & 3 & 3.7 \\
Isolated swelling & 1 & 1.3 \\
TOTAL & $\mathbf{8 0}$ & 100 \\
\hline
\end{tabular}

Painful swelling was the major indication in nearly half of the cases (95\%).

Table 4. Global distribution according to pathologies found.

\begin{tabular}{ccc}
\hline PATHOLOGY & EFFECTIVE & PERCENTAGE \% \\
\hline Orchi-epididymitis & 24 & 30 \\
Epididymitis & 48 & 60 \\
Orchitis & 8 & 10 \\
TOTAL & 65 & 100 \\
\hline
\end{tabular}

Epididymitis was the most common pathology (60\%).

(40\%) followed by students (30\%). The large painful bursa was the almost constant presenting features ( $95 \%$ of cases) and fever was associated in less than half of the cases (45\% of cases). Scrotal involvement was mostly unilateral (85\% of cases) and the left side was involved in 70\% of cases. Epididymitis (Figure 1 and Figure 2) was the most frequent pathology (60\%) followed by orchiepididymitis 
Table 5. Distribution according to ultrasound findings.

\begin{tabular}{|c|c|c|c|}
\hline Anatomical Structure & Ultrasound sign & Effective & Percentage $\%$ \\
\hline \multirow{2}{*}{ Epididymis } & - Homogeneous thickening & -36 & 50 \\
\hline & Heterogeneous thickening & $-\quad 36$ & -50 \\
\hline \multirow{2}{*}{ Testicle } & - Homogeneous hypertrophy & -24 & 75 \\
\hline & Heterogeneous hypertrophy & - & 25 \\
\hline \multirow{2}{*}{ Vaginal } & - Hydrocele & $-\quad 48$ & 60 \\
\hline & - No effusion & $-\quad 32$ & 40 \\
\hline \multirow{2}{*}{ Envelopes } & - Thickened & -80 & -100 \\
\hline & - Normal & -0 & - \\
\hline \multirow{2}{*}{ Vessels } & - Hyper vascularization & -24 & 30 \\
\hline & - $\quad$ Normal & 56 & 70 \\
\hline
\end{tabular}

Epididymis was thickened in $100 \%$ of cases. There was an increase in the size of the testis in $75 \%$ of cases and a heterogeneous appearance was either localized or focal in $25 \%$ of cases.

Table 6. Distribution according to the identified germs.

\begin{tabular}{ccc}
\hline GERM & EFFECTIVE & PERCENTAGE \% \\
\hline Chlamydiae trachomatis & 3 & 21.5 \\
Neisseria gonorrhae & 6 & 42.9 \\
Salmonella & 1 & 7.1 \\
E. Coli & 1 & 7.1 \\
Staphylococcus aureus & 2 & 14.3 \\
No germ & 1 & 7.1 \\
TOTAL & 14 & 100
\end{tabular}

Neisseria gonorrhae (42.9\%) and Chlamidya trachomatis (21.5\%) were the most commonly encountered germs.

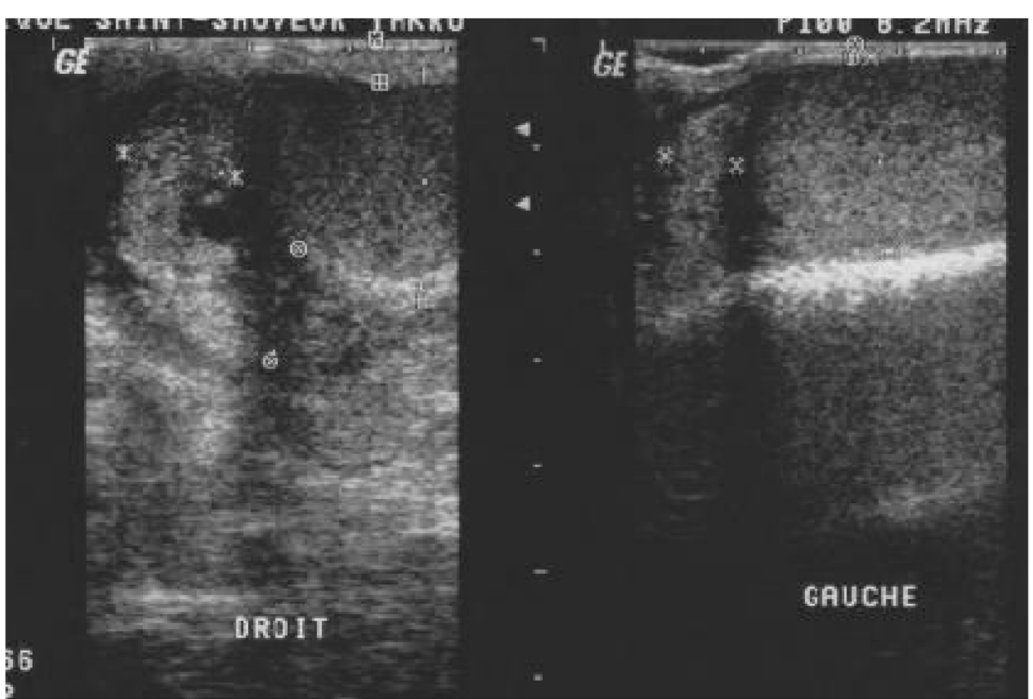

Figure 1. 19-year-old patient. Painful right scrotal swelling. Scrotal ultrasound performed in B mode using an $11 \mathrm{MHz}$ probe. Global hypertrophy of the right epididymis with thickening of the envelopes as opposed to the left side. Diagnosis retained: right epididymitis. 


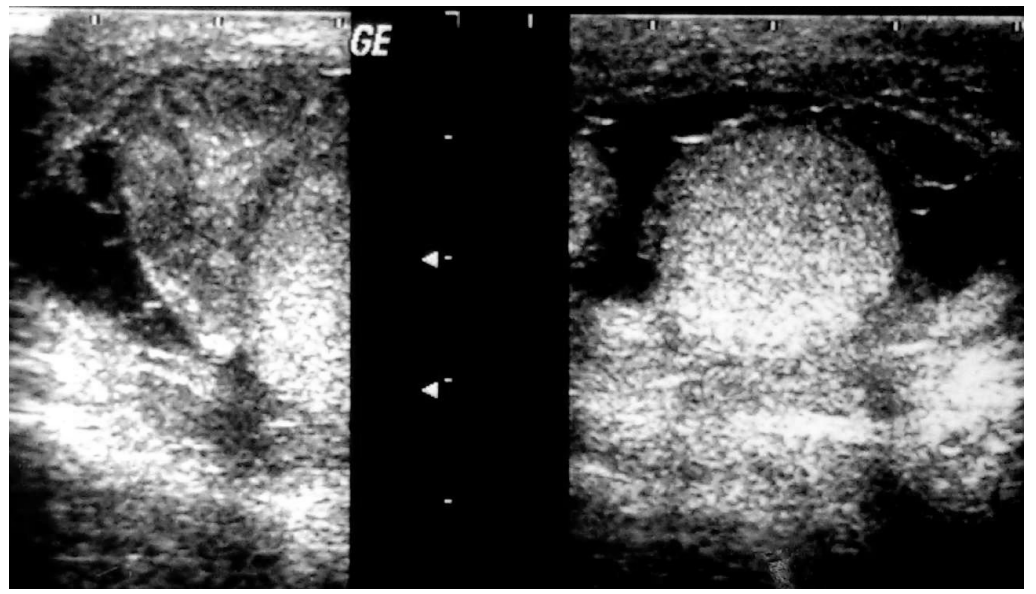

Figure 2. 21 year-old Patient. Painful right scrotal swelling. Scrotal ultrasound performed in B mode using an $11 \mathrm{MHz}$ probe. Global hypertrophy of the head of the right epididymis with thickening of the envelopes and reaction hydrocele with filaments. Diagnosis retained: chronic right epididymitis.

(30\%) and orchitis (10\%). Semeiologically, the epididymis was thickened in $100 \%$ of cases. This thickening involved the whole epididymis in $60 \%$ of cases, the head in $30 \%$ of cases and the tail in $10 \%$ of cases. The appearance was heterogeneous with the presence of abscess in $30 \%$ of cases and $20 \%$ of cyst. In $50 \%$ of cases the thickening was homogeneous. Regarding orchitis (Figure 3), there was an increase in the size of the gland in $75 \%$ of cases and a heterogeneous appearance either localized or focal in $25 \%$ of cases.

The most common accompanying ultrasound findings were envelope thickening (100\%), intravaginal fluid effusion (60\%), and Doppler hyper-vascularization (30\%). Biological examinations revealed in 6 cases Neisseriae Gonorrhae and 3 cases of Chlamydiae Trachomatis, 2 cases of Staphylococcus aureus, 1 case of Salmonella and 1 case of E. Coli. In 1 case no germ was found.

\section{Discussion}

Our study reveals that scrotal infectious pathology in Abidjan concerns young subjects with an average age of 23 years and a predominance of the age group ranging between 20 and 30 years. Our results agree with those of Mittmeyer [5] who in a retrospective study of 610 cases in the United States Army found that the incidence peak was 20 - 29 years (49\% of cases), within $70 \%$ of cases patients aged 20 - 39 years. It is the same for studies carried out by Klesser [6] in France and Agoda in Togo. In these studies the average age of patients was 21 years. The average age of patients was higher in England [7] according to Doble (28 years) and in the Ivory Coast [8] according to Kouassi B (27 years old).

According to the literature, this is an affection related to sexually active subjects, thus explaining the extreme youth of the population but also the most exposed profession. In our work, soldiers were the most represented, followed by students. According to Ryan P. Smith [9], epididymitis is the leading cause of hospitalization among soldiers in India. In the US, according to Luzzi, it is the 


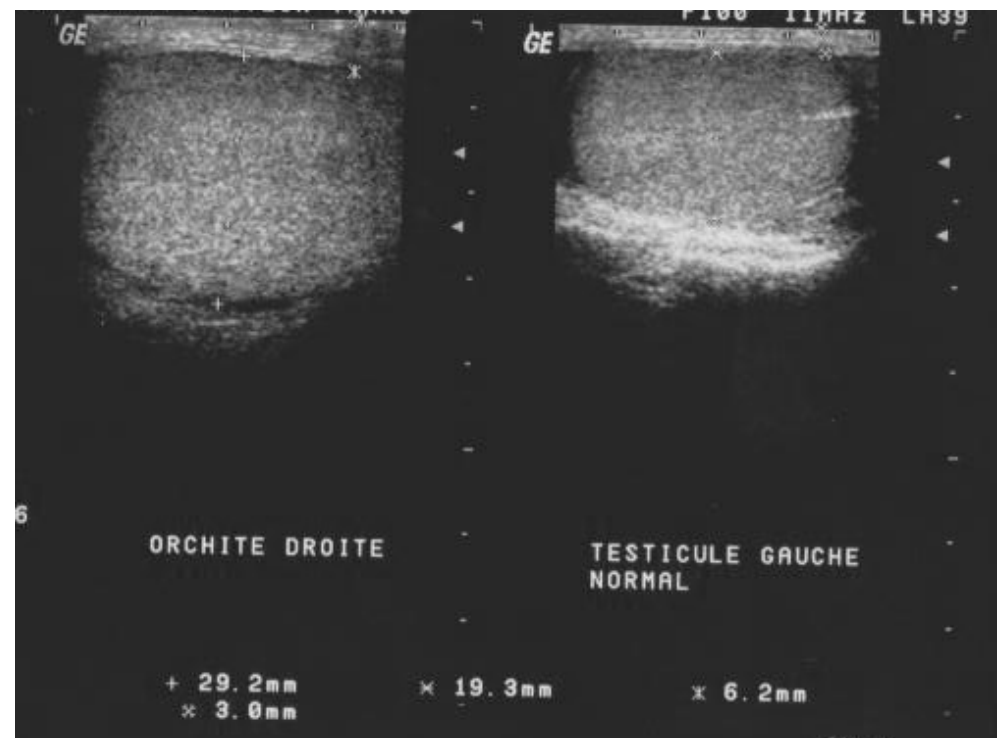

Figure 3. 26 year-old Patient. Painful right scrotal swelling. Scrotal ultrasound performed in B mode using an $11 \mathrm{MHz}$ probe. Heterogeneous overall hypertrophy of the right testis with thickening of the envelopes as opposed to the left side. Diagnosis retained: orchitis.

first urological affection observed during the military service and the consequence of this, a 3 week-hospitalization and a reduction of the time of the military service. Kouassi in Abidjan found 50\% of students in his population.

Presenting features of scrotal infectious pathology were dominated by the large painful bursa in our study associated with fever in $46 \%$ of cases. Hence the notion of Aubert's large hot bursa [10] in opposition to the large cold bursa that includes pathologies such as hydrocele, inguinoscrotal hernia. According to this author, in the case of infection of scrotal contents, the patient presents an acute large bursa, fever and urinary signs (dysuria, pollakiuria). Fever was present in the study of Ouattara et al. in 52\%. One-sidedness was essential in our study at $85 \%$. We agree with data from the literature [3] [10]. According to Luizi [10], bilateral epididymitis is rare and could account for only $9 \%$ in the best series, which is explained by consecutive involvement.

The left bursa was the most concerned at $70 \%$. This predominance of the left scrotal involvement was demonstrated by Kouassi in $100 \%$ of cases. The only case of tuberculousorchitis described by Agoda et al. was lateralized to the left. We are in contradiction with Luizzi et al. who consider that acute epididymitis involves the right and left sides with equal frequency.

Pathologically, our study showed that epididymitis was the most common pathology $(60 \%)$ followed by orchiepididymitis $(30 \%)$ and orchitis (10\%). We agree with the literature that demonstrates primary epididymal involvement before secondary orchid contamination. According to Roy, primary infectious testicular involvement is right away bilateral and of viral origin (Mumps Orchitis), which is the prerogative of children, although in a small proportion the adult could be affected. Ouattara et al. demonstrated $100 \%$ of orchiepididymitis (Figure 4) in their work. According to them, due to late consultation, the patients 


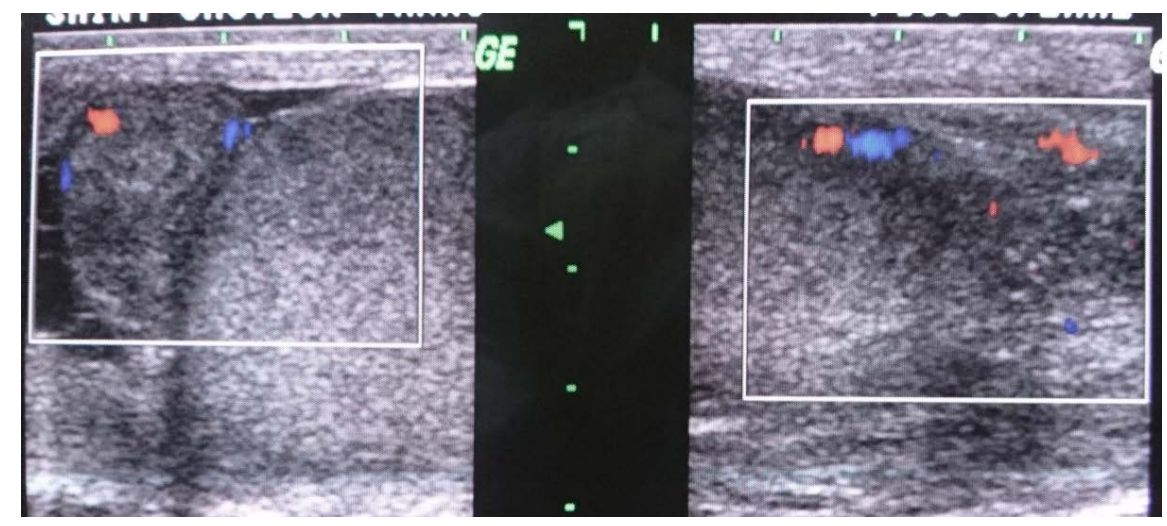

Figure 4. 20 year-old Patient. Left painful and febrile scrotal swelling. Scrotal ultrasound performed in B mode coupled with color Doppler using a $7.5 \mathrm{MHz}$ probe. Hypertrophy of the head of the left epididymis with thickening of the envelopes and a reaction hydrocele. Heterogeneous swelling of the testicle. Hypervascularization of the head of the epididymis and a testicular focus. Diagnosis retained: left orchiepididymitis.

would have first developed epididymitis and consulted traditional healers before going to hospital in the orchiepididymitis stage.

Radiologically, scrotal analysis was performed in B mode and in Doppler mode using an $11 \mathrm{MHz}$ probe. According to ROY, scrotal analysis must be done in high resolution with spectral studies associated. Contrast ultrasound is used by other authors in this pathology in order to make the difference between a tumor nodule and a pseudo-tumor orchitis [6] or between a zone of infarction and a tumor [11].

Semeiologically, we have demonstrated direct signs and signs of accompaniment. Concerning epididymitis, the thickening was demonstrated in $100 \%$ of cases. This thickening involved the whole epididymis in $60 \%$ of cases, the head in $30 \%$ of cases and the tail in $10 \%$ of cases. The appearance was heterogeneous with the presence of abscess in $30 \%$ of cases and $20 \%$ of cyst. In $50 \%$ of cases the thickening was homogeneous.

Regarding orchitis, there was an increase in the size of the gland in $75 \%$ of cases and a heterogeneous appearance either localized or focal in $25 \%$ of cases.

The most commonly encountered ultrasound accompanying findings, whether epididymitis, orchitis or the combination of both were envelope thickening (100\%), intravaginal fluid effusion (60\%) and Doppler Hypervascularization (30\%).

Our results agree with those of Pilatz et al. [12]. In their work epididymitis was primarily located in 24 cases (17.9\%) in the head, 52 cases $(38.8 \%)$ in the tail, and 58 cases $(43.3 \%)$ in the entire epididymis. abscesses and Doppler Hypervascularization as well as hydrocele accompanied epididymitis in $5.9 \%$, $100 \%$ and $45.5 \%$, respectively.

These ultrasound findings have also been described by Roy et al. to whom epididymitis appears as hypoechoic hypertrophy of the epididymis with envelope thickening and marked Doppler Hypervascularization.

For Gonzalez et al. [13], hydrocele, hematocele, pyocele, abscess and infarc- 
tion are more complications than accompanying or indirect signs.

The heterogeneous appearance of the testis was found by Agoda et al. [4] who described a multi-micronodular appearance related to a tuberculous involvement. In our study, there was no histopathological study or intra-scrotal sampling. This explains why we have not found a tuberculous etiology. However, sexually transmitted infections such as gonorrhea and chlamydial infection have dominated our etiologies. Our results are in contradiction with those of Ouattara in Mali which show that the predominant germs were Staphylococcus, Escherichia coli and streptococcus. This difference can be explained by the extreme youth of our population. Indeed, according to Bruce [13], acute Chlamydiae trachomatis orchiepididymitis represent one third of the cases in young adults. This assertion is confirmed by the study by Luzzi [14] who found a higher proportion of sexually transmitted germs followed by banal germs dominated by $E$. coli.

\section{Conclusion}

Considered as a common pathology, scrotal infections are widely explored on ultrasound worldwide. The technique that consists in using a high frequency probe associated with the color Doppler helps make positive diagnosis, look for complications and eliminate the other noninfectious pathologies. Our study showed that scrotal infectious pathology in Abidjan was most often encountered among young soldiers or students most often presenting a \pm febrile painful large bursa. This pathology is most often represented by total epididymal hypertrophy associated with Doppler Hypervascularization and accompanied by complications such as abscesses and hydrocele. Sexually transmitted germs were the predominant etiologies. Sexual education of young people, the fight against STIs could help prevent scrotal infectious pathology in sub-Saharan Africa.

\section{Conflict of Interest}

None.

\section{References}

[1] Douaihy, N., Benamran, D.A., de Gorski, A., Poletti, P.A. and Iselin, C.E. (2011) Torsion testiculaire : une urgence piège. Revue Médicale Suisse, 7, 2404-2408.

[2] Ouattara, K., Dafe, S.I., Yakwe, Y. and Cissé, C. (1991) Enquête sur les grosses bourses en milieu tropical. Médecine d Afrique Noire, 38, 850-855.

[3] Roy, C. and Tuchmann, C. (2003) Echographie scrotale. Journal of Radiology, 84, 581-595.

[4] Agoda-Koussema, L.K., Tchaou, M., Adjénou, V., Sonhaye, L., Anoukoum, T., Tengué, K., Amouzou, K. and N’Dakena, K. (2011) Testicule hétérogène à l'échographie: Penser également à la tuberculose après le cancer en zone d'endémie. Médecine Tropicale, 71, 100.

[5] Mittemeyer, B.T., Lennox, K.W. and Borski, A.A. (1996) Epididymitis: A Review of 610 Cases. Journal of Urology, 95, 390-392.

[6] Kessler, E., Paulhac, P., Delcleve-Paulhac, S., Colombeau, P. and Dumas, J.-P. 
(2003) Forme pseudo-tumorale de l'orchi-épididymite à chlamydiae trachomatis. Progrès en Urologie, 13, 1392-1393.

[7] Doble, A., Taylor-Robinson, D. and Thomas, B.J. (1989) Acute epididymitis: A Microbiological and Ultrasonographic Study. British Journal of Urology, 63, 90-94. https://doi.org/10.1111/j.1464-410X.1989.tb05132.x

[8] Kouassi, B., Horo, K., Gbazi, C., Ngom, A., Koffi, N., Aoussi, R.D., Aka, N., Aké, C., Kakou, D., Ahui, B., Godé, C., Aka-Danguy, E. and Itchy, M.V. (2009) Orchiepididymite tuberculeuse à propos de 2 cas enregistrés en pneumologie au CHU de Cocody. Mali Médical, 24, 68-70.

[9] Smith, R.P., Tracy, C.R., Kavoussi, P.K., Witmer, M.T. and Costabile, R.A. (2013) The Impact of Color Doppler Ultrasound on Treatment Patterns of Epididymitis in a University-Based Healthcare System. Indian Journal of Urology, 29, 22-26. https://doi.org/10.4103/0970-1591.109979

[10] Aubert, D. and Moro-Enemuwe, A. (2008) Pathologie génito-scrotale chez le garçon et chez l'homme. La revue du praticien, 58, 2289-2297.

[11] Lung, P.F., Jaffer, O.S., Sellars, M.E., Sriprasad, S., Kooiman, G.G. and Sidhu, P.S. (2012) Contrast-Enhanced Ultrasound in the Evaluation of Focal Testicular Complications Secondary to Epididymitis. American Journal of Roentgenology, 199, W345-W354. https://doi.org/10.2214/AJR.11.7997

[12] Pilatz, A., Wagenlehner, F., Bschleipfer, T., Schuppe, H.C., Diemer, T., Linn, T., Weidner, W. and Altinkilic, B. (2013) Acute Epididymitis in Ultrasound: Results of a Prospective Study with Baseline and Follow-up Investigations in 134 Patients. European Journal of Radiology, 82, e762-e768. https://doi.org/10.1016/j.ejrad.2013.08.050

[13] Bruce, A.W., Chadwick, P., Willettw, S. and O’Shaughnessy, M. (1981) The Role of Chlamydiae in Genitourinary Disease. Journal of Urology, 126, 625-629.

[14] Luzzi, G.A. and O’Brien, T.S. (2001) Acute Epididymitis. BJU International, 87, 747-755. https://doi.org/10.1046/j.1464-410x.2001.02216.x

\section{Submit or recommend next manuscript to SCIRP and we will provide best service for you:}

Accepting pre-submission inquiries through Email, Facebook, LinkedIn, Twitter, etc. A wide selection of journals (inclusive of 9 subjects, more than 200 journals) Providing 24-hour high-quality service

User-friendly online submission system

Fair and swift peer-review system

Efficient typesetting and proofreading procedure

Display of the result of downloads and visits, as well as the number of cited articles Maximum dissemination of your research work

Submit your manuscript at: http://papersubmission.scirp.org/

Or contact ojrad@scirp.org 